\title{
ESTADO, SOCIEDADE E CONTROLE SOCIAL NO PENSAMENTO JURÍDICO-PENAL NO GOVERNO VARGAS - 1930/1945
}

\author{
ESTADO, SOCIEDAD Y CONTROL SOCIAL EN EL PENSAMIENTO JURÍDICO-PENAL \\ EN EL GOBIERNO VARGAS - 1930/1945
}

\author{
STATE, SOCIETY AND SOCIAL CONTROL IN THE LEGAL-PENAL THOUGHT \\ UNDER VARGAS' GOVERNMENT - 1930-1945
}

\section{ETAT, SOCIETE ET CONTROLE SOCIAL DANS LA PENSEE JURIDICO-PENALE SOUS LE GOUVERNEMENT VARGAS - 1930/1945}

DOI: 10.5533/1984-2503-20102504

Rivail Carvalho Rolim

\section{RESUMO}

O período compreendido entre os anos 1930 e 1945 foi marcado por profundas mudanças sociais, políticas e econômicas na sociedade brasileira. Em função dessas transformações houve uma redefinição dos termos da vivência, que foi desde a participação mais ativa do Estado na vida social até a construção de um ideário que valorizava o coletivo em detrimento do individual. $\mathrm{O}$ objetivo deste artigo é analisar o papel assumido pelo sistema jurídico-penal no controle da criminalidade, bem como os mecanismos que foram utilizados pelo Estado para garantir a ordem social. Palavras-chave: ideias jurídico-penais, controle social, regime republicano.

\section{RESUMEN}

El periodo comprendido entre los años 1930 y 1945 fue marcado por profundos cambios sociales, políticos y económicos en la sociedad brasileña. A la luz de estos cambios hubo una redefinición de los términos de la vivencia social, que fueron desde una participación más activa del Estado en la vida social hasta la construcción de una ideología que valora lo colectivo sobre lo individual. El objetivo de este trabajo es analizar el papel que tiene el sistema de justicia penal en el control de la delincuencia, así como los mecanismos que fueron utilizados por el Estado para garantizar el orden social. Palabras-clave: ideas jurídico-penales, control social, régimen republicano. 


\section{ABSTRACT}

Brazilian society has been highlighted by deep social, political and economical changes during the 1930-1945' period. These transformations led to redefine the terms of the real life experience that spanned between the more active participation of the State in social life to the building of a set of ideas that valued community to the detriment of individuals. The objective of this paper is to analyze the role played by the legal-penal system in the control of criminality, as well as the mechanisms that were used by the State to reinforce social order.

Keywords: legal-penal ideas, social control, republican regime.

\section{RÉSUMÉ}

Au Brésil, la période 1930-1945 a été marquée par de profonds changements sociaux, politiques et économiques. Ces transformations ont provoqué une redéfinition des termes de ce vécu, qui allaient d'une participation plus active de l'État à la vie sociale à la construction d'un l'ensemble d'idées valorisant le collectif au détriment de l'individuel. L'objectif de cet article est d'analyser le rôle assumé par le système juridico-pénal dans le contrôle de la criminalité, ainsi que les mécanismes que l'État a utilisé pour garantir l'ordre social.

Mots-clefs : idées juridico-pénales, contrôle social, régime républicain.

Os debates sobre a mudança do ordenamento jurídico-penal brasileiro promulgado no início da década de 1940 são de singular importância para analisarmos as ideias acerca dos termos da vivência social do Governo Vargas, regime político que ainda hoje provoca muitas polêmicas e suscita pontos de vista divergentes. Quando tratamos desse período, é impossível tangenciar seu significado e a importância que possui seu principal líder político para a história do Brasil no século XX.

Não é sem sentido que encontramos trabalhos de diferentes áreas sobre o Governo Vargas e inúmeras teses interpretativas. Desde as teses clássicas sobre revolução e revolução passiva ${ }^{1}$, passando por aquelas sobre populismo ${ }^{2}$ e totalitarismo ${ }^{3}$ para chegar

\footnotetext{
${ }^{1}$ Fausto, Boris (1997). Revolução de 1930: história e historiografia, São Paulo: Cia das Letras; Vianna, Luiz Werneck (2004). A revolução passiva, Rio de Janeiro: Revan.

${ }^{2}$ Weffort, Francisco (2003). O populismo na política brasileira, Rio de Janeiro: Paz e Terra.

${ }^{3}$ Cancelli, Elizabeth (1993). O mundo da violência, Brasília: Ed. Unb.; Lenharo, Alcir (1994). Sacralização da política, Campinas: Papirus.
} 
até a do trabalhismo ${ }^{4}$, inúmeros trabalhos foram produzidos. Isso demonstra o significado e a relevância do regime político que se iniciou em 1930 e foi até 1945, bem como a força do seu legado.

Quando nos deparamos com algumas palavras, proferidas por um membro do poder judiciário logo após a fundação do Estado Novo e a outorga de uma carta constitucional pelo Presidente da República, no sentido de que uma nova legislação civil e criminal deveria ser elaborada para assegurar os interesses da defesa coletiva contra os crimes comuns, a segurança interna e externa do país contra os delitos políticos e sociais $^{5}$, consideramos que se atribuiu uma importância significativa aos princípios e postulados presentes no ordenamento jurídico-penal aprovado durante a vigência do Estado Novo.

A mudança da ordem jurídica era vista como necessária para adaptar a legislação penal ao novo Estado Social do governo varguista ${ }^{6}$. Francisco Campos, que foi ministro da Justiça e, inclusive, escreveu a exposição de motivos do novo Código Penal, defendia que o país possuísse "leis modernas sem modernismos, construídas num plano doutrinário homogêneo, sem perder de vista a realidade, inspirada no supremo interesse da Pátria, sem se confinar no jacobinismo"”.

Diante dessas evidências, entendemos que se faz necessário um trabalho mais aprofundado de reflexão sobre os debates durante o Governo Vargas que levaram à reformulação de todo o ordenamento jurídico-penal, visto que não encontramos trabalhos mais sistematizados sobre essa temática, principalmente no que diz respeito ao papel que o sistema penal teria no controle social de comportamentos vistos como antijurídicos ou antissociais $^{8}$. Trabalhamos com a perspectiva teórica de que o sistema penal cumpre esta função sobre as denominadas condutas desviadas, tendo em vista que o Estado tem o controle do poder punitivo ${ }^{9}$. Neste caso estamos utilizando a noção de controle social enquanto papel do Estado de organizar a sociedade, e não enquanto mecanismo

\footnotetext{
${ }^{4}$ Gomes, Angela de Castro (2003). A invenção do trabalhismo, Rio de Janeiro: Ed. Campus.

${ }^{5}$ Araujo, J. Correa de (1939). "O projeto do código criminal do Brasil". Revista Forense, Rio de Janeiro, Vol. 78, Abril de 1939.

${ }_{7}^{6}$ Duarte, José (1941). "O novo código penal". Revista Forense, Rio de Janeiro, vol. 87, Agosto de 1941.

7 Campos, Francisco. "A consolidação da ordem jurídica brasileira". Revista Forense, Rio de Janeiro, vol. 87, agosto de 1941.

${ }^{8} \mathrm{O}$ trabalho que encontramos sobre pensamento jurídico-penal não foca exclusivamente o Governo Vargas. Serra, Carlos Henrique Aguiar (1997). História das ideias jurídico-penais no Brasil: 1937-1964. Tese (Doutorado em História) - Instituto de Ciências Humanas e Filosofia, Universidade Federal Fluminense, Niterói.

${ }^{9}$ Bergalli, Roberto (Coordinador y colaborador) (2003). Sistema penal y problemas sociales, Valencia: Tirant lo Blanch, p. 33-35
} 
integrador ou orientador dos segmentos sociais, sentido em que foi empregada pela sociologia estadunidense do início do século $\mathrm{XX}^{10}$.

Parece-nos que a intelectualidade não considerou os postulados presentes no ordenamento jurídico-penal promulgado no início da década de 1940 como importantes para o entendimento desse período da história do país ${ }^{11}$. Encontramos pesquisas sobre 0 pensamento jurídico, mas em relação à legislação social. Talvez a força do legado dos direitos sociais na cidadania do país tenha ofuscado as reflexões sobre os postulados presentes no código jurídico-penal. Não é sem sentido a força desse legado, pois muitos trabalhadores falam que a carteira profissional pode ser considerada uma certidão de nascimento cívico, tal a importância atribuída à Consolidação das Leis do Trabalhado, promulgada em $1943 .^{12}$

Quando José Duarte e Francisco Campos defendem que as mudanças devem se adaptar às novas condições políticas do país, aproveitamos para destacar os pressupostos teóricos de que as práticas jurídicas não podem ser analisadas sem se levar em consideração a realidade histórica. Como diz Von Savigny, expoente da Escola Histórica de Direito da Alemanha, a essência do direito positivo é o fato de não ser estático e oferecer uma sucessão contínua de progressos. Com isso, necessitamos conceder-Ihe a característica da mutabilidade no tempo ${ }^{13}$. Antônio Manuel de Hespanha acrescenta um aspecto importante: a prática jurídica corresponde a uma efetiva reclamação por parte da realidade social, econômica e política ${ }^{14}$.

Neste sentido, destacamos que, ante as mudanças produzidas com a chegada de Vargas ao poder em 1930 - como, por exemplo, um papel mais destacado do Estado na regulação da vida econômica e social, na resolução dos conflitos entre trabalhadores e empresários ${ }^{15}$ e na criação de leis de assistência social -, para o pensamento jurídicopenal brasileiro era necessário que o país também atualizasse as normas de acordo com os novos tempos, os novos princípios da vida social.

$\mathrm{Na}$ realidade, os principais agentes políticos que levaram Vargas ao poder em 1930 tinham como objetivo introduzir uma nova forma de organização da vida social no país. Defensores das ideias do Positivismo propugnavam uma maior intervenção do Estado na

\footnotetext{
${ }^{10}$ Para uma análise mais sistematizada sobre os conceitos de Estado e controle social, consultar: Melossi, Dario (1992). El Estado del control social, Madrid: Siglo XXI editores.

${ }^{11}$ Promulgados: Código Penal (Decreto Lei 2848 de 07/12/1940); Código de Processo Penal (Decreto Lei 3688 de 03/10/1942); Lei de Contravenções Penais (Decreto Lei 3689 de 03/10/1942).

${ }_{12}$ Gomes, Angela de Castro (1982). "A construção do homem novo: o trabalhador brasileiro". In Oliveira, Lucia Lippi et alii. (1982). Estado Novo, ideologia e poder, Rio de Janeiro: Zahar.

${ }^{13}$ Von Savigny, Friedrich Carl (2004). O sistema do direito romano atual, ljuí: Editora Unijuí, p. 30.

${ }_{15}^{14}$ Hespanha, Antonio M. (1978). A história do direito na história social, Lisboa: Livros Horizonte, p. 73.

${ }^{15}$ Cerqueira Filho, Gisálio (1982). A “Questão Social” no Brasil. Crítica do Discurso Político, Rio de Janeiro: Civilização Brasileira.
} 
vida econômica e social, assim como uma revisão dos princípios individualistas, com afirmação do coletivo e do social. Vargas chega a falar que o Estado é o cérebro da Nação, devendo ter um equilíbrio ultraclassista e ser suficientemente forte para mediar os conflitos. Adepto do ideário positivista, o presidente entendia que o progresso do país só ocorreria quando se passasse da situação de desequilíbrio para uma de equilíbrio, que garantisse a justa proporção entre os elementos do conjunto ${ }^{16}$.

Neste caso, o pensamento jurídico entendia que o código jurídico-penal teria uma função importante neste novo cenário, como orientador e coordenador da dinâmica social. Os principais argumentos eram que o direito de punir liberal e individualista havia se tornado inadequado, pois os problemas estavam mais complexos. Quanto ao novo momento pelo qual passavam as estratégias de controle social, Zaffaroni assinala que "um dos fatores mais importantes para a transformação parcial do poder punitivo foi a concentração urbana, que aumentou consideravelmente o número de indesejáveis e também as dificuldades de seu controle social"17. Interessante que justamente naquele final do século XIX ocorreu o processo de criação e internacionalização de uma série de organizações que buscavam desenvolver normas universais para enfrentar os problemas delitivos. $^{18}$

Um argumento importante aparece nas palavras de José Duarte: o de que não se pode negar ao sistema jurídico o direito a transformações sociais ou políticas quando seus postulados estão inadequados em face dos novos imperativos éticos. Para esse membro do poder judiciário, as doutrinas, os sistemas e os cânones variam no tempo e no espaço. Por conseguinte, faz-se necessária uma profunda refundição, ou mesmo uma renovação de base e de substância da ordem legal. Elevando o direito à condição de ciência, enfatiza que esta não pode se furtar "à lei da evolução e, muitas vezes, a verdade numa época não é a verdade em outra". ${ }^{19}$

O pensamento jurídico estava fazendo referência às mudanças sociais que estavam ocorrendo nos principais países ocidentais e na sociedade brasileira, não só no aspecto político, mas também no jurídico. De fato, a passagem de um Estado liberal para um Estado intervencionista, na qual o governo passava a agir mais diretamente na organização da vida social, regulando e controlando as relações entre os segmentos sociais e os indivíduos, aparece também na ordem jurídica. Seguindo o ideário do intervencionismo estatal do final do século XIX, entendia-se que os segmentos sociais

\footnotetext{
${ }^{16}$ Bosi, Alfredo (2002). Dialética da colonização, São Paulo: Cia das Letras.

17 Zaffaroni, Eugenio Raul (2007). O inimigo no direito penal, Rio de Janeiro: Revan/ICC, p. 45.

${ }^{18}$ Olmo, Rosa Del (2004). A América Latina e sua criminologia, Rio de Janeiro: Revan/ICC, p. 75.

${ }^{19}$ Duarte, J. (1941). Op. cit.
} 
incorporados à sociedade moderna que não se adaptavam ao ambiente social deveriam ser submetidos a um processo de reeducação e recuperação para voltar ao convívio social. Como diz Mássimo Pavarini, para que os excluídos da cidadania e do pacto social sejam incluídos devem ser educados e disciplinados. ${ }^{20}$

Nessa crítica ao direito de punir individualista e liberal está a defesa de um sistema legal que pudesse proteger melhor os interesses do Estado. Essas mudanças legais teriam implicações significativas na capacidade legal, haja visto que se redefiniam os termos da vivência social com uma nova atribuição de direitos e deveres aos indivíduos, segundo a qual, por exemplo, estes deveriam ficar subordinados aos interesses estatais. Os argumentos para essa nova forma de governabilidade podem ser encontrados nas palavras de Nelson Hungria. Para este, que foi um dos principais membros da Comissão Revisora do Código Penal, "o indivíduo não pode ser o único fim do Estado", por conseguinte, deve-se fazer a "revisão dos princípios individualistas". Chega a dizer que o individualismo romântico de Rousseau não era mais possível e que jamais teria sido praticado em toda a sua pureza filosófica. ${ }^{21}$

Segundo Nelson Hungria, era necessário redefinir os termos de organização da vida social, pois o liberalismo político era marcado pela indiferença, pela pasmaceira e pela "quietude de quem só espera do acaso ou da providência dos céus". Ao sair em defesa do Estado Novo, ressalta que o regime político e social varguista "não obedece a místicas, a ideologias artificiais, a concepções iluministas", pois a "ortodoxia do demoliberalismo, o laissez faire, o laissez passer, era a indisciplina, o preâmbulo da anarquia, o princípio do caos"22.

Não obstante, se Nelson Hungria dirigia suas críticas ao direito penal liberal, em igual medida apontava-as para os Estados nazifascistas e comunistas. Uma delas, por exemplo, é que um "Estado todo-poderoso, seja Estado totalitário ou Estado marxista, exige o aniquilamento do indivíduo". Sobre a ordem jurídica alemã, com certo pesar, diz que os alemães "não se apercebem que um direito penal fora ou além das leis não seria um avanço, mas um recuo da civilização jurídica”23. Fazia questão de enfatizar o distanciamento do país em relação à ordem jurídica alemã, que, entre outras coisas, nesse período havia elaborado um projeto de lei com o intuito de tratar os estranhos à

\footnotetext{
${ }^{20}$ Pavarini, Massimo (2009). Castigar el enemigo: criminalidad, exclusión e inseguridad, Ecuador: Flacso, p. 47.

${ }_{21}$ Hungria, Nelson (1937). "O direito penal autoritário". Revista Forense, Rio de Janeiro, Vol. 71, Julho/Agosto/Setembro de 1937.

${ }_{22}$ Hungria, Nelson (1941). "O direito penal no Estado Novo". Revista Forense, Rio de Janeiro, Vol. 85, jan/fev/mar de 1941.

${ }_{23}^{23}$ Hungria, N. (1937). Op. cit.
} 
comunidade com seleção eugênica, controle mediante internação e eliminação física de inúmeros segmentos sociais considerados marginais ${ }^{24}$.

O criminalista defendia que 0 indivíduo não podia ser esmagado pelo rolo compressor do Estado ou ser brutalmente imolado a um despótico interesse coletivo. Em sua opinião, posições radicais para a direita (Alemanha) ou para a esquerda (União Soviética) "não eram mais que colapsos ou retrocessos na evolução política dos povos". $\mathrm{Na}$ defesa que fazia do regime político do Estado Novo ressaltava que o direito penal brasileiro assegurava os interesses da ordem coletiva, quando em conflito com os postulados da liberdade individual. Além do mais, a experiência pela qual estava passando o país "demonstrava a necessidade de um reajustamento de normas e condições de existência entre o todo social e o indivíduo, entre o Estado e a célula individual, $^{\text {25. }}$.

Diante dos extremos em curso no continente europeu, Nelson Hungria dizia que "o justo caminho era o meio termo". Para esse criminalista, o regime instaurado em 1937 "já não compreende o indivíduo alheio ao Estado ou fora do Estado"; em outros termos, "já não mais se permite que a parte se ponha em contraste com o todo", à medida que o "ponto de mira do Estado deixou de ser o indivíduo e passou a ser a coletividade, o total dos indivíduos". Apesar disso, o Estado Novo "não desconhece a capacidade realizadora do indivíduo, mas cuida de canalizá-la, de utilizá-la no interesse do bem geral e, portanto, do próprio indivíduo". Em outras palavras, quando houvesse divergência entre os interesses individuais e os da coletividade, deveria ocorrer a intervenção retificadora do Estado, para garantir o equilíbrio e a harmonia. ${ }^{26}$

Nas palavras de Hungria, a ordem jurídica do Estado simplesmente processou um reajustamento de seus interesses, tornando-se intervencionista. Dizia com ênfase que, contrariamente à Alemanha e à Rússia, o Estado Novo implantou o princípio de autoridade e com isso reassumiu em "toda a plenitude, o seu jus imperii, a sua inabdicável soberania". Com esta nova forma de organização social, o alvo do Estado deixou de ser o indivíduo e passou a ser a coletividade, a totalidade dos indivíduos. Asseverava que no novo regime político

(...) não mais se permite que a parte se ponha em contraste com o todo. (...) a salvaguarda dos interesses gerais reclama uma série de limitações à liberdade, não somente para garantir a liberdade igual

\footnotetext{
${ }^{24}$ Conde, Francisco Muñoz (2003). Edmundo Mezger y el derecho penal de su tiempo: estudios sobre el derecho penal en el nacionalsocialismo, Valencia: Tirant lo Blanch, p. 175

${ }^{25}$ Hungria, N. (1941). Op. cit.

${ }^{26}$ lbidem.
} 
de cada indivíduo, mas, principalmente, para fazer convergir a atividade individual para os escopos gerais, comuns a coletividade. ${ }^{27}$

Para Hungria ${ }^{28}$, o país seguia uma trajetória própria em relação aos postulados organizadores da vida social, e o código jurídico-penal havia acendido uma vela a Carrara e outra a Ferri. Esse ecletismo resultava da cultura jurídica brasileira, que não abria mão dos postulados do classicismo penal, mas incorporava vários fundamentos trazidos pelo positivismo penal e pela criminologia. Quanto a essa representação social sobre a cultura jurídica, consideramos que as leis e a instituições penais "sempre se propõem, analisam, legislam e funcionam dentro de códigos culturais definidos", conforme destaca David Garland ${ }^{29}$.

No tocante a essa forma de entender o funcionamento do processo de construção das normas jurídicas, David Garland destaca que os valores e as mentalidades influenciam as instituições penais. Para este sociólogo, que tem produzido clássicos trabalhos sobre o castigo e renovado as perspectivas de investigação nesta área, "a moral $e$ as sensibilidades se colocam na trama dos interesses e posições sociais de maneira que refletem a complexa realidade da vida cultural". Acrescenta que, para entendermos como funciona a penalidade, temos que entender que ela está

(...) marcada em linguagens, discursos e sistema de signos que encarnam significados culturais determinados, distinções e sentimentos que é preciso interpretar, entender se queremos compreender o significado social e os motivos do castigo. ${ }^{30}$

A construção social de que o Estado varguista representava a população pode ser encontrada nas palavras de um dos mais importantes pensadores de matriz autoritária no país. Segundo Oliveira Vianna, no governo que se iniciou com a Revolução de 1930 havia uma "tendência visível e definida do Estado a identificar-se com o povo e do povo a se identificar com o Estado". Propugnando pela existência de um Estado corporativo, usa uma linguagem carregada de emoção para salientar que o governo revolucionário encontrou a técnica mais perfeita para realizar a obra de integração social do próprio povo, ao arrancá-lo do atomismo individualista e colocá-lo em novas formas de solidariedade social e nacional ${ }^{31}$.

\footnotetext{
${ }^{27}$ Ibidem.

${ }^{28}$ Hungria, Nelson (1942). "O arbítrio judicial na medida da pena". Revista Forense, Rio de Janeiro, vol. 89, Janeiro de 1942.

${ }_{29}$ Garland, David (1999). Castigo y sociedad moderna: un estudio de teoría social, Madrid: Siglo XXI Editores, p. 233.

30 Ibidem.

${ }^{31}$ Vianna, Oliveira (1940). "A política social da revolução brasileira". Revista Forense, Rio de Janeiro, Vol. 84, Out./Nov/dez de 1940.
} 
Para esse agente político, o Governo Vargas, dono de uma visão pragmática e realista, soube colocar a questão social dentro da realidade nacional, e com isso reabilitou a massa de trabalhadores. Procura também tipificar a experiência histórica vivida pela sociedade brasileira a partir de 1930 ao salientar que o governo teve uma ação de benemerência, de bom senso, de equilíbrio, de extraordinário alcance humano. Com a intenção de construir um simbolismo em torno do que representava a nova situação vivida pela sociedade brasileira, argumenta que foi a solução "mais harmoniosa, mais sensata, mais justa, mais consentânea, não só com a nossa estrutura econômica e social, como com a nossa própria índole nacional, com as condições específicas da nossa própria psicologia coletiva,32.

A linguagem utilizada por Oliveira Vianna é carregada de um simbolismo que procura dominar a realidade social. Apresenta, por exemplo, como algo real na vida cotidiana dos brasileiros o sentimento de união, de tranquilidade, de solidariedade social e, especialmente, profissional. Essa representação social traz como pressuposto a ideia de que o Brasil e o povo brasileiro devem rechaçar os postulados do individualismo, dos enfrentamentos e do ódio entre as classes. Para este que é um dos mais importantes intelectuais do pensamento social brasileiro, com o governo que se inicia no episódio de 1930, o povo estava liberto das influências perturbadoras vindas de terras estrangeiras. ${ }^{33}$

Embora Nelson Hungria e Oliveira Vianna ressaltassem que o país estava vivenciando uma experiência diferenciada ao adotar novos princípios de vivência social com o Governo Vargas, temos de destacar que o pressuposto de que o Estado ou a sociedade política tem por fim o bem comum e de que os governantes agem em consonância com os interesses da coletividade está presente no pensamento ocidental desde a Antiguidade Clássica. Quando Hungria dizia que o Estado varguista existia antes da parte e Oliveira Vianna afirmava que o Estado e o povo, nas suas expressões mais autênticas e genuínas, estavam unidos numa obra comum e solidária, nada mais faziam do que seguir um legado presente na cultura jurídico-política ocidental.

Quanto à união existente entre o Estado e o povo, Michel Foucault, por exemplo, mostra como se arraigou na cultura política das sociedades ocidentais o postulado de que os homens são como um rebanho que é conduzido por um pastor. Salienta que, embora estivesse presente em várias civilizações da antiguidade, foi com os hebreus que se intensificou o tema pastoral. No cristianismo católico, está muito presente a concepção do "Deus-pastor e seu rebanho de homens". Essa concepção de Deus-pastor foi transferida

\footnotetext{
32 Ibidem.

33 Ibidem.
} 
para o líder político, que assumiu a função de guiar o rebanho. Esse líder que conduz pode velar, escutar e prestar atenção a todos do seu rebanho enquanto dormem. ${ }^{34}$

Quanto ao fato de atacar o individualismo e reforçar a ideia de que o Estado existe antes das partes, podemos recuperar o pensamento político aristotélico em seu clássico livro sobre a política. Uma das passagens em que esse postulado fica claro é aquela em que o filósofo grego diz que no Estado ou sociedade política o "todo existe necessariamente antes da parte". Os argumentos são de que as

(...) sociedades domésticas e os indivíduos não são senão partes integrantes da cidade, todas subordinadas ao corpo inteiro, todas distintas por seus poderes e suas funções, e todas inúteis quando desarticuladas, semelhantes às mãos e aos pés que, uma vez separados do corpo, só conservam o nome e a aparência, sem a realidade, como uma mão de pedra. ${ }^{35}$

Destarte, para o filósofo grego os interesses da comunidade estão em primeiro plano, em detrimento do particular, pois o bem de um só homem não era um fim último, tendo-se em vista a necessidade de buscar o bem comum. Para Tomás de Aquino, outro pensador ocidental muito presente no pensamento jurídico-político brasileiro, assim como o homem era parte de um lar, igualmente o lar constituía parte da cidade. Para esses dois filósofos, os governos sempre se organizam visando ao bem comum, à felicidade de todos.

Outro aspecto que devemos destacar do pensamento de Tomás de Aquino diz respeito à forma como ele entende a organização da vida social. Segundo este que é considerado o filósofo maior do cristianismo católico, a comunidade baseia-se na hierarquia. $\mathrm{O}$ argumento é que, se na ordem celeste ou na Cidade de Deus está presente a desigualdade, pois há uma gradação dos méritos, assim deve ser também na Cidade do Homem. Logo, se havia a desigualdade, segundo o pressuposto paulino, era porque possuíamos diferentes dons segundo a graça que nos foi dada. Com essa construção social da realidade se justificava a hierarquia, a desigualdade e a obediência, que, em última instância, garantiam a concórdia e a união ${ }^{36}$.

Em nossa opinião, fica bastante evidenciado que a redefinição dos termos da vivência social do Governo Vargas está bastante influenciada por este pensamento jurídico-político, por demais arraigado na história das sociedades ocidentais. Neste caso, o pensamento político clássico, que forjou a construção do mundo moderno, é visto como

\footnotetext{
${ }^{34}$ Foucault, Michel (1990). "Omnes et singulatim: por uma crítica da 'razão política”. Novos Estudos Cebrap n. 26, Março de 1990, p. 77-99.

${ }^{35}$ Aristóteles (2002). A política, São Paulo: Martins Fontes, p. 5.

${ }^{36}$ Thomás de Aquino (1997). Escritos políticos de Santo Thomas de Aquino, Petrópolis: Vozes.
} 
algo estranho à realidade brasileira. Mesmo com toda a força dos postulados da modernidade, continua-se acreditando que o poder do soberano deriva do pai, e não de um contrato estabelecido autonomamente pelos cidadãos, mantendo, com isso, o pressuposto de que o Estado é uma grande família.

Sobre essa representação social de que o Estado é uma instância de integração dos agrupamentos sociais, de que visa ao bem comum e aos interesses nacionais, Sérgio Buarque de Holanda, em seu clássico trabalho Raízes do Brasil, escrito justamente quando essa experiência histórica estava em curso no país, alertava que não há uma continuidade, mas uma oposição. Todavia, um aspecto chama a atenção nas reflexões desse renomado historiador brasileiro, que diz respeito às fontes que utiliza para mostrar essa incompatibilidade.

Sérgio Buarque de Holanda não recorre a Platão ou Aristóteles, mas a Sófocles, pois, segundo ele, foi este último que exprimiu com mais intensidade o antagonismo entre o Estado e o povo. Destaca o excerto de quando Antígona sepulta Polinice contra as ordens do Estado, encarnado na figura do irmão Creonte. Com esta atitude atrai para si a cólera do irmão, que age em nome não de sua vontade pessoal, mas da suposta vontade geral dos cidadãos. Com esse clássico da tragédia grega, procura mostrar muito como o Estado e o indivíduo/família estão em franca oposição. Conclui seu raciocínio destacando que "Creonte encarna a noção abstrata, impessoal da Cidade em luta contra essa realidade concreta e tangível que é a família". ${ }^{37}$

Não obstante, as fontes utilizadas pelo pensamento jurídico-penal brasileiro não são da tragédia grega. Podemos ver isso claramente nas palavras de Romão Cortes de Lacerda, membro do poder judiciário, quando argumenta que o Estado Novo, com sua renovação política e social, veio valorizar os agrupamentos tradicionais que sempre constituíram a Nação Brasileira ${ }^{38}$. Os argumentos são de que no regime do Estado Novo o homem estava subordinado à finalidade das instituições, embora fosse independente em sua parte moral e espiritual. Para outro membro do poder judiciário, o pensamento político clássico acreditou no antagonismo do Estado e do indivíduo, enquanto o do século XX quer conciliá-los, à medida que a "ação individual deve ser ajustada a ação coletiva". ${ }^{39}$

\footnotetext{
${ }^{37}$ Holanda, Sérgio Buarque de (1995). Raízes do Brasil. São Paulo: Cia das Letras, p. 141.

38 Lacerda, Romão Cortes de (1943). "A indissolubilidade do casamento e as ações de nulidade e anulação". Revista Forense, Rio de Janeiro, vol. 93, Março de 1943.

${ }^{39}$ Lima, Augusto Sabóia (1940). "O Estado e o indivíduo". Revista Forense, Rio de Janeiro, vol. 82, Abril de 1940.
} 
Foi justamente com a ideia de que as partes deviam se ajustar ao coletivo e o Estado devia ter um controle maior sobre a dinâmica social que uma nova ordem jurídicopenal foi introduzida no país. Para os principais criminalistas, estava sendo criado o maior número possível de figuras penais e procedimentos judiciais, para que o Estado tivesse as melhores condições de reagir contra atos que porventura lograssem romper a paz, a ordem e a tranquilidade social. Por conta disso, Nelson Hungria dizia que o Estado não poderia ficar equidistante dos problemas da criminalidade no país, como um "guarda modorrento que só se desperta a um rumo alto e se limita a soprar no seu apitado assustadiço e inócuo". 40

Para manter a tranquilidade, a paz e a ordem social em meio aos debates para a mudança do ordenamento jurídico-penal começou-se a fazer críticas no sentido de que somente as penas não eram suficientes para fazer frente à criminalidade em curso no país. Narcélio de Queiróz, um dos membros da Comissão Revisora do Código Penal, dizia que esta sanção penal era inútil como corretivo em relação a certas classes de delinquentes: os profissionais e os incorrigíveis em geral ${ }^{41}$. Como assinala Massimo Pavarini, no paradigma etiológico está implícito o postulado de que a diversidade criminal tem um fundamento ontológico-natural, como se a ação desviante e o homem delinquente fossem realidades naturais, mas não efeitos de um processo político-cultural que define certo comportamento humano como crime ou certo sujeito como criminoso ${ }^{42}$. Para Alessandro Barata, este paradigma carrega consigo a premissa que a criminalidade é algo pré-constituído às definições ou reações institucionais ou não institucionais. ${ }^{43}$

Para o pensamento jurídico-penal, o Estado não podia somente punir as pessoas, devia pensar em uma forma de discipliná-las para que se integrassem à sociedade com vista ao interesse geral da coletividade. Para Oscar Stevenson, sob a influência do cristianismo católico,

(...) entre as atribuições do Estado e sua reconhecida ação social está não só de segregar, se for necessário, o agente perigoso, mas dispensar-Ihe assistência tutelar, ampará-lo, tratá-lo, corrigi-lo, vigiálo, erguê-lo de sua miséria física e moral, desfazendo as causas e ocasiões do delito ${ }^{44}$.

\footnotetext{
${ }^{40}$ Hungria, N. (1941). Op. cit.

${ }^{41}$ Campos, Francisco et alli (1941). "O novo código penal". Revista Forense, Rio de Janeiro, vol. 85, janeiro de 1941.

${ }_{42}$ Pavarini, Massimo (2002). Control social y dominación: teorías criminológicas burguesas y proyectos de dominación, Buenos Aires: Siglo XXI Editores, p. 44.

${ }^{43}$ Baratta, Alessandro (2004). Criminología y sistema penal, Montevideo-Buenos Aires: Editorial Bdef, p. 90.

${ }^{44}$ Stevenson, Oscar (1944). "Pena e medida de segurança". Rio de Janeiro, Revista Forense, vol. 98, Maio de 1944.
} 
Destarte, em suas palavras encontramos a ideia de que a pena é a medicina da alma e de que a punição constitui uma ação racional e consciente de luta anticriminal portanto, bem alinhada aos preceitos do correcionalismo, corrente segundo a qual o Estado deve proporcionar ajuda aos delinquentes, a quem consideravam os mais necessitados do corpo social, justamente por sua incapacidade para levar uma vida jurídica livre. $^{45}$

Quanto a isso, vale destacar que os principais argumentos eram que o código jurídico-penal era destinado aos inferiores, vistos dessa forma por serem considerados incapazes de aceder ao mundo das ideias, para usarmos as palavras de Zafaroni quando busca a origem da legitimação discursiva do tratamento penal diferenciado ${ }^{46}$. $\mathrm{Na}$ realidade, os inferiores eram os que possuíam algum tipo de deficiência cultural e biopsicológica decorrente da multiplicidade étnica da sociedade brasileira. Basileu Garcia, um dos principais criminalistas do período, disse enfaticamente que as ações penais se destinavam aos "elementos malos viventes, por isso, perigosos" 47 . Por sua vez, Nelson Hungria se empenhava em assinalar que o código penal era destinado àqueles com inferioridade psíquica, que só existiam porque havia uma "subespécie de homo sapiens $^{\prime 48}$. Acrescentando a opinião de mais um criminalista que participou muito ativamente nos debates, para Oscar Stevenson, a pena tinha como objetivo o aperfeiçoamento da criatura humana inferiorizada. ${ }^{49}$

Não podemos deixar de destacar a opinião de outro criminalista acerca dos alvos do sistema jurídico, pois apresenta um componente novo: a de que as leis penais estavam destinadas aos pobres, pois, carecendo de formas de ócio e comodidades, aumentavam a família. O resultado era uma população subalimentada e com taras que provocavam um aumento de anormais nas prisões e hospitais. Sobre esse aspecto, desde o início do século havia acirradas discussões sobre as punições que deviam ser aplicadas aos indivíduos com perturbações mentais no caso de cometerem algum tipo de delito, pois não eram considerados penalmente capazes ou imputáveis ${ }^{50}$. Segundo o pensamento jurídico-penal, o dilema era que se tratava de pessoas inocentes para

\footnotetext{
${ }^{45}$ Beiras, Iñaki Rivera. (Coord.) (2005). Política criminal y sistema penal. 2 $2^{\mathrm{a}} \mathrm{ed}$, Barcelona: Anthropos.

${ }^{46}$ Zaffaroni, E. R. (2007). Op. cit, p. 83.

${ }^{47}$ Garcia, Basileu (1945). "Medidas de segurança". Revista da Faculdade de Direito de São Paulo, São Paulo, vol. 40.

${ }^{48}$ Hungria, Nelson (1947). "Discurso inaugural da I Conferencia Panamericana de Criminologia ocorrida no Distrito Federal e em São Paulo". Revista Forense, Rio de Janeiro, Vol. 114, novembro de 1947.

${ }^{49}$ Stevenson, O. (1944). Op. cit.

${ }_{50}$ Azevedo, Noé (1943). "Da responsabilidade criminal". Revista Forense, Rio de Janeiro, vol. 95, setembro de 1943.
} 
ficarem na prisão, mas perversas demais para permanecerem internadas nos manicômios.

Quanto à permanência nas instituições judiciais, de fato, a nova legislação penal regulou e facilitou a aplicação de sanções penais àqueles tipificados como perigosos, pois, além das penas, foram criadas as medidas de segurança. Quando da criação destas sanções penais na Europa, foi considerado um conjunto sistemático de procedências de cunho preventivo individual que iria cumprir uma função importante em relação à periculosidade, pois faria o sequestro, por tempo indeterminado, do autor, já que só permitiria sua volta à sociedade se estivesse completamente readaptado à vida honesta $\mathrm{e}$ livre.

$\mathrm{Na}$ sociedade brasileira, de acordo com o Código Penal, os indivíduos considerados perigosos seriam submetidos a medidas de segurança pessoais detentivas e não detentivas. As primeiras consistiam em reclusão em manicômios judiciais, em casas de custódia e tratamento, em colônias agrícolas e institutos de trabalho, de reeducação ou de ensino profissional. As segundas consistiam em liberdade vigiada, proibição de frequentar determinados lugares e exílio local ${ }^{51}$.

Cabe uma referência às pessoas consideradas perigosas no ordenamento jurídicopenal, as quais deveriam ser submetidas às medidas de segurança. Conforme a Lei das Contravenções Penais, eram aquelas condenadas por motivo de contravenção cometida em estado de embriaguez pelo álcool ou substância de efeitos análogos, quando fosse habitual a embriaguez (art. 14), por entregar-se habitualmente à ociosidade (art. 59) ou por mendigar por ociosidade ou cupidez (art. 60). Estavam enquadrados nesta tipificação também aqueles que eram reincidentes em explorar ou realizar a loteria denominada de jogo do bicho (art. 58) e estabelecer ou explorar jogo de azar em lugar público ou acessível ao público (art. 50) ${ }^{52}$.

Como podemos ver, ocorre um processo de criminalização dos desocupados, mesmo porque um dos grandes objetivos do Governo Vargas era transformar o homem em cidadão trabalhador, responsável por sua riqueza individual e também pela riqueza do conjunto da Nação; ou seja, trabalhar era um direito e um dever do homem, uma obrigação para com a sociedade e para com o Estado ${ }^{53}$. Não obstante, esse processo de disciplinamento e controle social passava também pelo código jurídico-penal, e não somente pela legislação social.

\footnotetext{
${ }^{51}$ Código Penal de 1940. Decreto-Lei 2848, de 07/12/1940. Artigos 75 a 101.

52 Lei das Contravenções Penais. Decreto-Lei 3688 de 03/10/1941

${ }^{53}$ Gomes, A. C. (1982). Op. cit.; Gomes, A. C. (2004). Op. cit.
} 
Essas sanções penais poderiam ser impostas no momento da sentença, durante o período de execução da pena ou quando a pessoa, mesmo que livre, fosse considerada um perigo para a sociedade. $O$ argumento central era que, se somente se aplicasse a pena, o condenado poderia sair das instituições penais mesmo ainda representando perigo à sociedade. Para os criminalistas, esta sanção judicial atacava justamente a reincidência, porque não podia haver uma revogação se não se comprovasse a ausência de periculosidade do delinquente. Para exemplificarmos, os condenados por vadiagem ou mendicância e os reincidentes no jogo do bicho ou outro tipo de jogo de azar eram internados em colônias agrícolas ou em institutos de trabalho, de reeducação ou de ensino profissional. ${ }^{54}$

É neste sentido que, para Nelson Hungria, a ordem jurídico-penal de 1940 tratou de enfrentar a criminalidade de três pontos de vista: o científico-experimental de suas causas; o político, na adaptação às medidas destinadas a preveni-la e a coibi-la; e o jurídico, de sistematização das normas que regulam a relação entre o delinquente e o Estado $^{55}$. Jimenez de Asúa, importante criminalista espanhol, em sua obra Tratado de Derecho Penal, faz referência ao ordenamento jurídico-penal brasileiro, dizendo que este tem o mesmo aspecto político-criminal de outros códigos elaborados nesta conjuntura, pois contém um conjunto de princípios de investigação científica do delito e de eficácia das penas ${ }^{56}$.

Diante das palavras de Jimenez de Asúa de que o código penal brasileiro apresentava essas características, podemos afirmar que se aproximava de outras experiências jurídicas do continente europeu, evidenciando uma apropriação de ideias por parte do pensamento jurídico-penal pátrio, mesmo porque os principais criminalistas do país participavam dos congressos internacionais sobre temas que envolviam o sistema jurídico-penal. Na realidade, os brasileiros também comungavam as mesmas inquietações internacionais acerca da melhor forma de tratar com o conflito social. Disto são exemplo as discussões sobre se as medidas de segurança deveriam ou não substituir as penas, tema que foi discutido em um congresso realizado na cidade de Bruxelas em 1926. ${ }^{57}$

Em meio aos debates para a mudança do código penal, vários brasileiros - como Afrânio Peixoto, Alcântara Machado, Leonídio Ribeiro e Roberto Lyra, para citarmos alguns -, participaram do $1^{\circ}$ Congresso Internacional de Criminologia, realizado em Roma no ano de 1938. Neste evento, foram discutidos temas como etiologia e diagnóstico da

\footnotetext{
${ }^{54}$ Lei das Contravenções Penais. Decreto Lei 3688 de 03/10/1941. Artigo 15.

55 Hungria, N. (1947). Op. cit.

${ }^{56}$ Apud Beiras, I. R. (2005). Op. cit, p. 82.

${ }^{57}$ Olmo, R. Op. cit, p. 109 e 110.
} 
delinquência de menores, estudo da personalidade do delinquente e meios preventivos e terapêuticos da delinquência, como reformatórios, escolas para desviados e manicômios criminais. A pena aparece como meio de defesa da sociedade nacional, devendo cumprir uma função reabilitadora e intimidante..$^{58}$

A aplicação das medidas de segurança no Brasil guardava certa variável com os delitos. O acusado de cometer uma infração penal era internado por um prazo mínimo, sem direito de se submeter a nenhum tipo de exame de periculosidade. $O$ procedimento só seria realizado depois que o sentenciado tivesse cumprido o tempo mínimo estabelecido na sentença judicial. Não obstante, se havia um tempo mínimo, não estava estabelecido o máximo, pois isso dependia dos exames realizados; portanto o exame destinava-se somente a aumentar a pena, e nunca diminuí-la.

Diante disso, fica evidenciado que as medidas de segurança constituíam um poderoso instrumento de controle social da população, não só no momento em que foram criadas, mas também nos períodos subsequentes, haja visto que submetiam os segmentos sociais vistos como perigosos a um sistema de confinamento, muitas vezes, alheio às normas processuais. Em relação aos manicômios judiciais, se dizia que a viagem era somente de ida. Um dos criminalistas mais destacados do período, Noé Azevedo, chega a dizer que, embora o sofrimento do alienado fosse idêntico ao de um homem normal, continuar indefinidamente recluso era para o seu próprio bem. ${ }^{59}$

Neste sentido se começou a falar que no ordenamento jurídico-penal tinha sido introduzida de forma sub-reptícia a pena de prisão perpétua no país. Basileu Garcia é bastante esclarecedor quanto a esse aspecto quando diz que o reincidente em um delito doloso está sujeito a ficar segregado da sociedade por tempo ilimitado, ainda que se lhe imponha uma pena de prisão, justamente pelo caráter indeterminado de execução das medidas de segurança.

Aliado a esse aspecto da indeterminação das penas havia o problema de não se criarem instituições adequadas para o cumprimento das sanções penais. Basileu Garcia, dois anos depois da promulgação do Código Penal, dizia que na maioria das prisões do país os presos eram encarcerados como feras, quase sem ar, sem luz e sem poder ver outras pessoas. Recorrendo a Ferri, diz que a "cela é uma das aberrações do século XIX", portanto, o Brasil não poderia conviver com este sistema carcerário. ${ }^{60}$

\footnotetext{
58 Ibidem, p. 116 e 117.

59 Azevedo, Noé (1944). "Problemas penitenciários". Revista Forense, Rio de Janeiro, vol. 98, Abril de 1944.

60 Garcia, Basileu (1942). "Regimes adequados ao cumprimento das penas de reclusão e detenção estabelecimentos de prisão provisória". Revista da Faculdade de Direito da USP, São Paulo, vol. 37;
} 
Quanto ao caráter da indeterminação das penas e das condições inadequadas para o cumprimento das sanções penais, podemos recorrer às reflexões de Raul Zaffaroni sobre a política criminal latino-americana. Esse criminalista salienta, entre outras coisas, que, se na Europa estava vigente a concepção de Lizst e a idealização de um Estado de bem-estar social, abaixo da linha do Equador a ideia da defesa social surgiu como continuação do velho positivismo italiano, carregada de um componente organicista social vinculado ao ideário filosófico do bem comum de ordem tomista. Neste caso, o tratamento dos presos nunca chegou a ser mais do que uma declaração solene da letra da lei. Destaca, inclusive, que isto serviu como pretexto para diminuir a segurança jurídica e aumentar a margem de arbitrariedade política e judicial ${ }^{61}$. No entanto, o ordenamento jurídico-penal de 1940 seguiu orientando o funcionamento do sistema penal no país até a atualidade, com ligeiras modificações, que não chegaram a descaracterizar seus postulados.

Para finalizarmos, podemos concluir que, no Governo Vargas, o país passou por um grande processo de transformação dos princípios organizadores da sociedade e o sistema penal foi adaptado para se ajustar à nova realidade política imperante. Neste sentido, foram criadas novas sanções penais para que o Estado tivesse instrumentos de controle social de segmentos que atentavam contra a ordem e a tranquilidade.

\section{Bibliografia}

Aristóteles (2002). A Política, São Paulo: Martins Fontes.

Baratta, Alessandro (2006). Criminología y sistema penal, Buenos Aires: Editorial BdeF.

Beiras, Iñaki Rivera (Coord) (2004). Mitologías y discursos sobre el castigo, Barcelona: Anthropos.

(Coord.) (2005). Política criminal y sistema penal. $2^{\mathrm{a}}$ ed, Barcelona: Anthropos.

Bergalli, Roberto (Coord. y colab.) (2003). Sistema penal y problemas sociales, Valencia: Tirant lo Blanch.

(1944). "Cumprimento das penas de reclusão e detenção - estabelecimento de prisão provisória". Revista Forense, Rio de Janeiro, vol. 98, junho de 1944.

${ }^{61}$ Zaffaroni, Eugenio Raúl (1982). Política criminal latinoamericana, Buenos Aires: Editorial Hammurabi, p. 101 e 106. 
. (Ed) (1998). Contradicciones entre derecho y control social, Barcelona: Editorial M. J. Bosch.

Berger, Peter y Luckmann, Thomas (2008). La construcción social de la realidad, Buenos Aires: Amorrortu.

Bosi, Alfredo (2002). "A arqueologia do Estado-providência". In Dialética da colonização. São Paulo: Cia das Letras.

Cancelli, Elizabeth (1993). O mundo da violência, Brasília, Ed. Unb.

Cerqueira Filho, Gisálio (1982). A "Questão Social no Brasil. Crítica do Discurso Político, Rio de Janeiro: Civilização Brasileira.

Conde, Francisco Muñoz (2003). Edmundo Mezger y el derecho penal de su tiempo: estudios sobre el derecho penal en el nacionalsocialismo, Valencia: Tirant lo Blanch.

Fausto, Boris (1997). Revolução de 1930: história e historiografia, São Paulo: Cia das Letras.

Foucault, Michel (1990). "Omnes et singulatim: por uma crítica da 'razão política'. Novos Estudos Cebrap n. 26, Março de 1990, p. 77-99. . (1991). Vigiar e punir, Petrópolis: Vozes.

Garland, David (2008). A cultura do controle, Rio de Janeiro: Revan/ICC. . (1999). Castigo y sociedad moderna: un estudio de teoría social, Madrid: Siglo XXI editores.

Goffmann, Erving (2008). Estigma: la identidad deteriorada, Buenos Aires: Amorrortu.

Gomes, Angela de Castro (2003). A invenção do trabalhismo, Rio e Janeiro: Ed. Campus. 
. (1982). "A construção do homem novo: o trabalhador brasileiro". In Oliveira, Lucia Lippi et alli (1982). Estado Novo, ideologia e poder, Rio de Janeiro: Zahar.

Hespanha, Antonio M. (1978). A história do direito na história social, Lisboa: Livros Horizonte.

Holanda, Sérgio Buarque de (1995). Raízes do Brasil, São Paulo: Cia das Letras.

Lenharo, Alcir (1994). Sacralização da política. Campinas: Papirus.

Melossi, Dario (1992). El Estado del control social, Madrid: Siglo XXI editores.

Melossi, Dario e Pavarini, Massimo (2006). Cárcere e fábrica, Rio de Janeiro: Revan/ICC.

Olmo, Rosa Del (2004). A América Latina e sua criminologia, Rio de Janeiro: Revan/ICC.

Pavarini, Massimo (2009). Castigar el enemigo: criminalidad, exclusión e inseguridad, Ecuador: Flacso.

. (2002). Control y dominación: teorías criminológicas burguesas y proyectos hegemónicos, Buenos Aires: Siglo XXI Editores.

Rusche, Georg e Kirchheimer, Otto (2004). Punição e estrutura social, Tradução de Gizlene Neder, Rio de Janeiro: Revan/ICC.

Serra, Carlos Henrique Aguiar (1997). História das ideias jurídico-penais no Brasil: 19371964. Tese (Doutorado em História) - Instituto de Ciências Humanas e Filosofia, Universidade Federal Fluminense, Niterói.

Thomas de Aquino (1997). Escritos políticos de Santo Thomas de Aquino, Petrópolis: Vozes.

Vianna, Luiz Werneck (2004). A revolução passiva, Rio de Janeiro: Revan.

Von Savigny, Friedrich Carl (2004). O sistema do direito romano atual, ljuí: Editora Unijuí. 
Weffort, Francisco (2003). O populismo na política brasileira, Rio de Janeiro: Paz e Terra.

Zaffaroni, Eugenio Raul (2007). O inimigo no direito penal, Rio de Janeiro: Revan/ICC. . (1982). Política criminal latinoamericana, Buenos Aires: Editorial Hammurabi. 